\title{
Federalismo cooperativo brasileiro: implicações na gestão da educação municipal
}

\section{Brazilian cooperative federalism: implications for the management of municipal education}

\author{
Jean Mário Araújo Costa1 \\ Maria Couto Cunha² \\ Rosimeire Baraúna M. de Araújo³
}

\section{Resumo}

As características do modelo federalista adotado pelo Estado brasileiro é o tema central desse artigo. Especificamente, abordamos as questões relacionadas à educação através do viés da cooperação estabelecida em lei e que envolve as instâncias federal, estadual e municipal. O texto resulta de um levantamento bibliográfico que objetivou a compreensão do federalismo em seu aspecto conceitual, sua relação com o processo de descentralização e principalmente as relações intergovernamentais advindas dessa forma de organização, enfocando as implicações para gestão da educação municipal. As discussões apresentadas à luz da literatura demonstraram que apesar dos avanços oriundos da Constituição de 1988 e LDBEN de 1996 o pacto federativo ainda apresenta muitos desafios no tocante à cooperação para promover a educação nacional, situação que tem gerado implicação para os municípios brasileiros, instância que mantém relações de proximidade com a população e suas demandas.

Palavras-chave: Federalismo, Relações

Intergovernamentais, Educação Municipal.

\begin{abstract}
:
The central theme of this article is the characteristics of the federalist model adopted by the Brazilian state. Specifically, we addressed issues related to education through the bias of the cooperation established by law and that involves federal, state and municipal levels. The text results from a literature survey aimed to the understanding of federalism in its conceptual aspects, its relation to the process of decentralization and intergovernmental relations mainly stemming from this form of organization, focusing on the implications for management of municipal education. The discussion on the literature showed that despite the advances from the constitution of 1988 and 1996 LDBEN of the federative pact still has many challenges in terms of cooperation to promote national education, situation that has generated implication for Brazilian cities, that proceedings maintains close relations with the population and their demands.
\end{abstract}

Keywords: Federalism, Intergovernmental Relations, Education City.

\footnotetext{
1 Doutorando do Programa de Pós Graduação em Educação da Faculdade de Educação da Universidade Federal da Bahia. jmcosta.ufba@yahoo.com.br 2 Professora Adjunta da Faculdade de Educação da Universidade Federal da Bahia. mcouto@ ufba.br 3 Doutoranda do Programa de Pós Graduação em Educação da Faculdade de Educação da Universidade Federal da Bahia. rsbarauna@ hotmail.com
} 
O estudo sobre políticas públicas sociais, neste caso, as educacionais, não pode se alhear das reflexões sobre o federalismo como forma de organização do Estado Brasileiro desde 1889. O sistema federativo brasileiro, instituído juntamente com a República, foi outorgado como forma de preservar a unidade territorial, sob o signo de um pacto com as Províncias, assim elevadas à condição de unidades autônomas, além de promover-se como resposta à centralização unitária do período colonial e imperial que atravancava o desenvolvimento das bases econômicas e políticas.

Na década de 1990, a partir do agravamento da crise econômica mundial, diagnosticada como crise do Estado, foram tomadas algumas iniciativas para reduzir o Estado numa perspectiva de redimensionamento do seu papel. Nesse sentido, as políticas governamentais sinalizaram a racionalidade financeira, implicando na redução dos gastos públicos. Esse período também foi marcado pela focalização e intensificação de ações voltadas à reformulação da educação, principalmente nos aspectos financeiros, incentivando novos arranjos federativos nas responsabilidades assumidas pelas diferentes esferas governamentais no provimento da educação básica.

Nesse contexto, este trabalho tem a finalidade de apresentar algumas reflexões sobre a configuração das políticas do sistema federativo e seus reflexos no setor educação, procurando discutir os seguintes questionamentos: em que consiste o federalismo cooperativo brasileiro? Quais os delineamentos da descentralização nas políticas sociais, especialmente nas educacionais? Quais os impasses do modelo federativo cooperativo na gestão da educação municipal?

Para isso, o texto procura inicialmente apresentar uma breve trajetória conceitual e histórica, seguindo-se com uma reflexão acerca das relações entrefederalismo e descentralização, Federalismo e Relações Intergovernamentais e impasses do pacto federativo. Por fim, procura discutir algumas questões sobre as atuais políticas públicas educacionais, no contexto do federalismo cooperativo brasileiro a partir da Constituição de 1988.

\section{Conceito e origem do Federalismo}

Remonta ao século XVIII o surgimento do termo federalismo ${ }^{4}$, para designar a forma de organização implantada nos Estados Unidos, resultante da união territorial do poder de colônias para formar um Estado. Com a vitória na guerra de independência, foi criada uma confederação ${ }^{5}$ de estados livres e independentes, mas logo começaram a se manifestar os problemas relativos à necessidade de certa força do poder central que permitisse estabelecer a lei e a ordem, que regulasse o comércio, as dívidas e a negociações externas do país. Daí surgiu uma solução conciliatória, pactuada, estabelecida em convenção entre os entes confederados, que, do ponto de vista da organização política e administrativa, mantivesse a autonomia das unidades territoriais, ao mesmo tempo em que assegurasse a unidade nacional: federação.

Lijphart (1999 apud ARRETCHE, 2002, p. 26) define Estados federativos como "[...] forma particular de governo, dividido verticalmente, de tal modo que diferentes níveis de governo têm autoridade sobre a mesma população e território". Rodden (2005, p. 17) afirma que "[...] acordos formais e contratos implicam reciprocidade: qualquer que seja o propósito, os envolvidos devem cumprir alguma obrigação mútua". Já o regime de Estado Unitário ${ }^{6}$ se dá dentro de um governo central, com autoridade exclusiva de um Estado e com jurisdição integral em todo o país. "Não há autonomia das divisões administrativas, assim estas são diretamente subordinadas à autoridade do poder central mediante delegação". (CURY, 2006, p. 116)

4 Em 1786, Alexander Hamilton, James Madison e John Jay esforçaram-se para a divulgação jornalística constituída por uma série de 85 artigos chamados "federalistas", numerados segundo a ordem de publicação.

5 A confederação indica a união entre várias nações autônomas que se reúnem em torno de um só poder central que as representa ante as demais nações. Exemplo de confederação é a Suíça e a Bósnia Herzegovina. (CURY, 2006, p. 116)

6 Exemplos típicos de Estado Unitário: França, Uruguai, Portugal e Brasil imperial. (CURY, 2006, p. 116) 
Assim, o federalismo pode ser caracterizado como um pacto de um determinado número de unidades territoriais autônomas com vistas a finalidades comuns. Trata-se de uma organização político-territorial do poder cuja base é a dupla soberania: a dos entes federados (governos subnacionais) e a do governo central (União). Os primeiros têm autonomia para gerir questões locais, e o segundo tem a finalidade de representar e fazer valer os interesses de toda a população do país. Cury (2006, p. 114) define federação

[...] como uma união de membros federados, que formam uma só unidade soberana: o Estado. Ou seja, no caso do Brasil, é o que denominamos de União. No regime federal, só há um Estado Soberano, com unidades federadas subnacionais. Estas gozam de autonomia, cuja relatividade se dá dentro dos limites jurisdicionais atribuídos e especificados. Daí que tais subunidades não são nem nações independentes nem unidades somente administrativas.

Celina Souza (1998) chama a atenção para a emergência de formas federativas em países e em instituições que não são uma Federação e ainda a existência de grande variedade na prática dos princípios federais dentro de cada federação. Essa mesma autora afirma que "[...] a razão de ser do federalismo brasileiro sempre foi, e continua sendo uma forma de acomodação das demandas de elites com objetivos conflitantes, bem como um meio para amortecer as enormes disparidades regionais". (SOUZA, 1998, p. 575)

Assim, o federalismo desenvolvido no Brasil e amparado legalmente pela Constituição de 1988 se defronta com a amplitude geográfica, a diversidade econômica e capacidade de governabilidade que envolve o território nacional. Os impasses oriundos desse cenário político, econômico e estrutural geraram distintas posições acerca do debate sobre centralização e descentralização, bem como se fizeram distintos os rumos das políticas públicas na redefinição do papel do Estado no âmbito das reformas intensificadas nos anos 1990.

\section{Federalismo e Descentralização}

Como vimos anteriormente, o sistema federativo brasileiro foi instituído juntamente com a República, como forma de preservar a unidade territorial, além de promover-se como resposta à centralização unitária do período colonial e imperial que atravancava o desenvolvimento das bases econômicas e políticas.

Portanto, se nos Estados Unidos o federalismo surgiu como alternativa das tendências centralizadoras, no Brasil surgiu como alternativa à centralização política e administrativa no período colonial e imperial, predominando uma concepção que identificou o federalismo com maior descentralização. Contudo, essa concepção deve ser relativizada, "[...] na medida em que, como derivada da ideia de contrato social, a ideia de federação pode estar associada a uma lógica de perfil centralizador e até mesmo antidemocrático" (ARAÚJO, 2006, p. 5).

Convém salientar que a existência de um sistema político descentralizado não fornece subsídios necessários para qualificar um modelo federalista de organização do Estado. 0 federalismo pressupõe uma autonomia política e financeira, instituída por uma Constituição que determine a estrutura do Estado. Outra condição é a existência de mais de uma esfera de governo, para que essas se constituam autônomas nos âmbitos financeiro, administrativo e político. Soma-se a estes requisitos a indissociabilidade das esferas instituídas nacionalmente, bem como a repartição de competências por meio de um regime cooperativo de governo (CASSEB, 1999).

Considerando esses aspectos, a descentralização se torna um elemento importante para o federalismo, por permitir uma interlocução entre as instâncias governamentais ao tempo em que estas são dotadas de condições para gerir seus recursos e atender às demandas apresentadas pelas políticas locais. No caso do Brasil há autores que argumentam que não houve um processo de descentralização, mas de desconcentração. Essa constatação está vinculada à incapacidade da União em prover seus entes federados de condições técnicas e financeiras para gerir de forma autônoma suas políticas. Assim, a autonomia política se deparou com condições administrativas desfavoráveis em grande parte dos municípios brasileiros, comprometendo a implementação de políticas de forma articulada, reservando a estes a função de executores de propostas instituídas pela União. 
Com relação aos conceitos de descentralização e desconcentração, apesar de estarem relacionados com a forma de distribuição do poder nos estados modernos, existem diferenças fundamentais entre eles. Enquanto a descentralização implica transferência de competências e de poder, a desconcentração se limita à distribuição de tarefas, através da fragmentação e segmentação de políticas públicas, com vistas a um maior controle político e social pelo poder central. Isto quer dizer que, a descentralização resulta de um embate de forças por mais espaço de poder, na direção de um pacto que, explícita ou implicitamente estabeleça as relações e competências dos entes federados envolvidos. Daí entender-se a descentralização como intrínseca ao federalismo (EGLER; MATTOS, 2003).

Apesar dessa relação necessária entre federalismo e descentralização é importante observar que na prática, torna-se imprescindível que instâncias que dão unidade a este regime ultrapassem a condição de executores de políticas e avancem no sentido de construção de suas próprias leis e elaboração de estratégias próprias de alcance dos objetivos estabelecidos no âmbito local. Para tanto, faz-se mister o estabelecimento de relações baseadas no respeito mútuo e orientadas por uma iniciativa de intercolaboração entre as instâncias federadas, superando dessa forma a competitividade na provisão de serviços sociais.

\section{Relações Intergovernamentais na perspectiva do Federalismo Cooperativo}

Emmeados da década de 1940, como processo de abertura política após a superação do período de exceção do Estado Novo, o municipalismo ganhou contornos nítidos, como movimento reivindicatório que conseguiu assegurar, na Carta de 1946, dispositivos que previam a repartição de rendas e competências para os municípios. Um dos principais líderes desse movimento foi Rafael Xavier, que desde a década de 1930, debatia a necessidade de uma reforma tributária que levasse em conta uma discriminação de rendas favorável aos municípios.
Após o fim do regime ditatorial e a instauração de um processo de democratização política, a campanha municipalista foi retomada com a atuação do Instituto Brasileiro de Administração Municipal (IBAM). Ao lado disto, a redistribuição das receitas públicas para dotar as unidades federadas de maior autonomia financeira deu início a um percurso de mudanças fundamentais para a superação do conceito de estado centralizado. Esse processo de descentralização financeira foi seguido pela descentralização das competências entre as diferentes instâncias administrativas, principalmente no que diz respeito às políticas sociais. Com relação a esse fato, Egler e Mattos (2003, p. 427) afirmaram que

No Brasil, diferentemente de outros países na América Latina, a descentralização que culminou na Constituinte de 1988, não foi iniciativa do governo central, mas iniciou-se no final da década de 1970 junto com a crise econômica e a luta pela redemocratização, a partir dos governadores e prefeitos.

Já Arretche (2002) alerta que as reformas das instituições políticas ao longo dos anos, 1980 particularmente, a retomada de eleições diretas em todos os níveis de governo após a ditadura militar instaurada em 1964 e as deliberações da Constituição Federal de 1988 recuperaram as bases federativas do Estado brasileiro. Posteriormente, nos anos 1990, já completada a institucionalização do Estado Federativo, investiuse num extensivo programa de descentralização, particularmente na área das políticas sociais.

Variações do contexto histórico brasileiro concorreram para muitas flexibilizações conceituais, de maneira que é possível identificar três matrizes segundo o nível das relações intergovernamentais entre os entes federados, segundo Cury (2006, p. 115):

1. 0 federalismo centrípeto se inclina ao fortalecimento do poder da União, em que, na relação concentração/ difusão do poder, predominam relações de subordinação dentro do Estado Federal. Pode se dar como exemplo 0 próprio Brasil entre os anos 1930 e 1980, embora com uns acentos diferenciados para os períodos específicos, como 0 de 1946-1964.

2. 0 federalismo centrífugo se remete ao fortalecimento do poder do Estado membro sobre o da União, em que, na relação concentração/difusão do poder, prevalecem 
relações de larga autonomia dos Estados membros. Pode-se assinalar como tal a Velha República, especialmente entre 1898-1930.

3. 0 federalismo de cooperação busca um equilíbrio de poderes entre a União e os Estados membros, estabelecendo laço de colaboração na distribuição das múltiplas competências por meio de atividades planejadas e articuladas entre si, objetivando fins comuns. Esse federalismo político é o registro jurídico de nossa atual constituição.

A Constituição Federal de 1988 reconhece o Brasil como uma República Federativa formada pela união indissolúvel dos estados, municípios e do Distrito Federal. E ao se estruturar assim o faz sob o princípio da cooperação, de acordo com os artigos $1 .{ }^{\circ}, 18,23$ e 60 .

Para dar conta desse modelo federado e cooperativo, a Constituição de 1988 instituiu um ordenamento jurídico complexo de repartição de competências e atribuições, dentro de limites expressos, reconhecendo a dignidade e a autonomia, na qual coexistem competências privativas e competências concorrentes entre os entes federados. Comentando esse sistema Cury (2006, p. 121-122) afirma que,

A Constituição faz escolha por um regime normativo e político, plural e descentralizado na qual se cruzam novos mecanismos de participação com um modelo institucional cooperativo e recíproco que amplia 0 número de sujeitos capazes de tomar decisões. Por isso mesmo a cooperação exige entendimento mútuo entre os entes federados e a participação supõe a abertura de arenas públicas de decisão.

O primeiro limite para a operacionalização do desenho constitucional pautado na colaboração recíproca entre os entes federados, apontado por Cury (2006), advém da omissão de nossos parlamentares em não terem ainda elaborado a legislação complementar, exigida pela Constituição em seu parágrafo único do artigo $23^{7}$. Vale dizer que na educação, a EC 14 e a LDB 9394/96 apresentam melhor definição legal das incumbências e da abrangência das instâncias federal, estadual e municipal e dos próprios estabelecimentos escolares. (SAVIANI, 1997)

7 Leis complementares fixarão normas para a cooperação entre a União e os Estados, o Distrito Federal e os Municípios, tendo em vista o equilíbrio do desenvolvimento e do bem estar em âmbito nacional.
O federalismo cooperativo surgiu com a necessidade de atender às demandas sociais e se constituiu alternativa para resolução de problemas práticos, orientando-se pela possibilidade de desenvolver ações compartilhadas entre os níveis de governo. Nessa relação torna-se viável o estabelecimento de objetivos comuns, ao tempo que há respeito às formas de alcançá-los, considerando as distintas realidades que envolvem o território e a população de cada ente federado. Assim, nesse sistema deve haver uma independência na ação, preservando as peculiaridades locais.

Ao tempo em que a cooperação é uma condição necessária no regime administrativo brasileiro, algumas estratégias utilizadas para implementar políticas comuns comprometem sua efetividade. Exemplificando essa afirmativa, na área de educação, alguns programas e projetos são gestados na esfera federal e disponibilizados aos estados e municípios, que por não compreenderem aspectos importantes da essência desses projetos, ou por não possuírem condições técnicas e financeiras de atender aos requisitos, imputam mudanças na execução e em consequência alteram o alcance dos objetivos propostos.

\section{Impasses do Pacto Federativo}

Tomando em consideração a natureza dos problemas que caracterizam a crise do federalismo brasileiro, estudos de Barreto e Vigevani (2004) apontam que as dificuldades enfrentadas relacionam-se diretamente com as questões de maior complexidade, envolvendo a vasta extensão territorial, a existência de enormes desequilíbrios econômicos, políticos e sociais, intra e interregionais. Além disso, esses autores pontuam que a federação brasileira está requerendo um novo tipo de legitimidade que depende de um esforço de construção de cooperação, capaz de ir além dos acordos entre as elites dominantes, ou seja, de caminhar no sentido de institucionalizar também os interesses coletivos (BARRETO; VIGEVANI, 2004, p. 38-39).

Assim, podemos perceber que a natureza dos problemas do federalismo brasileiro demonstra que as dificuldades dos municípios brasileiros não se resolvem somente com as reformas 
tributárias; embora importantes, tais reformas revelam-se impotentes para consolidar um pacto capaz de aperfeiçoar a Federação brasileira no sentido de aproximá-la do seu conceito original.

Outra questão relevante é que a descentralização político-institucional na Carta de 1988 acompanhada da ampliação de recursos fiscais, das competências tributárias dos municípios, causou também o mais expressivo processo de fragmentação dos municípios brasileiros. Tomio (2005, p. 103) tem mostrado que essa situação "[...] despertou preocupações sobre as consequências da falta de estabilidade no ordenamento federativo, do desperdício fiscal e da instabilidade na gestão das políticas públicas".

Do ponto de vista legal ou administrativo, o município só existe por autorização ou delegação de poder jurídico superior, ou seja, a origem da instituição municipal depende sempre da vontade, da manifestação de um poder que Ihe é superior. Não obstante, a partir da Constituição de 1967 até o ano de 2000, a divisão territorial brasileira foi aprofundada. Por força constitucional, os Estados passaram a decidir sobre a criação de novos municípios, o que antes era de responsabilidade da União. Estudos de Faria (2006, p. 70) apontam que no período de 1988 até o ano de 2000 foram criados 1.438 municípios no Brasil (cerca de 25\% de todos os municípios), acelerando o processo de instabilidade institucional no ordenamento federativo e, consequentemente, a fragmentação municipal.

Em larga escala, essas iniciativas envolveram micro e pequenos municípios, até que, em 1996, com a recentralização normativa para a esfera da União, por meio da Emenda Constitucional 15/1996', ocorreu um refreio desse processo, significando que determinados acordos políticos entre estados e municípios deixariam de prevalecer no critério central de desmembramento dessas localidades.

No Brasil pós 1988 a autoridade política de cada nível de governo é soberana e independente das demais e, diferentemente de outros países,

8 A Emenda 15/96 retirou das unidades federadas a autonomia de regulamentar sua divisão políticoadministrativa interna. A partir dessa emenda o processo de fragmentação municipal voltou a ser regulamentado por Lei Complementar Federal. (TOMIO, 2005, p. 105) os municípios brasileiros foram declarados entes federativos autônomos. Com isto, a estrutura organizacional do sistema social vem sendo profundamente redesenhada a partir da implantação de programas de descentralização que vêm transferindo, paulatinamente, um conjunto significativo de atribuições de gestão para a esfera municipal.

Conforme já assinalado, a importância relativa dos governos municipais no Brasilvem sendo alçada a cada nova constituição federal, principalmente com a Constituição de 1988. Neste período, elevou-se consideravelmente o volume de recursos próprios dos municípios e em consequência, importantes tarefas, antes assumidas pela União ou pelo Estado, passaram a ser de responsabilidade do município. Para Celina Souza (2004), tais recursos, no entanto, são distribuídos de forma muito desigual, dada a grande heterogeneidade socioeconômica e demográfica do país. Além disso, no Brasil, a definição oficial de município não faz distinção entre tais localidades, considerando a enorme diversidade dos 5.564 municípios, nem mesmo em relação ao grau de urbanização e a separação entre áreas urbanas e rurais. Assim, analisar o papel que vem sendo desempenhado pelos governos locais, não é tarefa simples.

Nesse cenário, destaca-se que,

[...] embora a descentralização tenha sido um dos objetivos dos constituintes de 1988, estudos desenvolvidos apontam para a consolidação de políticas voltadas para a implementação de políticas sociais e não para 0 aumento da capacidade de decidir sobre onde e como investir os recursos (SOUZA, C., 2004, p. 34).

A transferência de responsabilidades depende ainda de estratégias indutivas desenhadas para delegar a implementação de uma dada política a outro nível de governo, de forma a superar os obstáculos à descentralização. Além disso, esse processo pode desencadear "[...] barganhas federativas, pelas quais cada nível de governo pretende transferir à outra administração a maior parte dos custos políticos e financeiros da gestão das políticas e reservar para si a maior parte dos benefícios dela derivado" (ARRETCHE, 1999, p. 115). 
Por esse motivo, o processo de descentralização das políticas sociais no Brasil só pode ser substancial na medida em que as administrações locais avaliem as suas condições técnicas, políticas e financeiras a partir da assunção das atribuições de gestão, ou, pelo menos, que considerem que os custos com os quais deveriam arcar poderiam ser minimizados pela ação dos demais níveis de governo.

A descentralização das políticas sociais em nível local configurou-se com mais intensidade na municipalização da provisão dos serviços universais de saúde e educação, exclusivamente no ensino fundamental, sendo que ambas as políticas foram concebidas como um sistema complexo de relações intergovernamentais baseadoem recompensas esanções. Geralmente, nesse processo, os entes federados dotam-se de características autoritárias. Isso se resume na seguinte situação, a instância federal pretende agir como determinante sobre a estadual e esta sobre a municipal.

O federalismo se configura como técnica pragmática (WATTS, 2002), por isso, os efeitos gerados nas relações estabelecidas entre as esferas envolvidas dependem das condições de cada realidade, o que origina também experiências diversificadas. Além disso, essas relações são desenvolvidas em um campo de tensões intergovernamentais, vez que a legislação não determina com clareza as atribuições de cada ente, gerando ao poder local a responsabilidade de atender as demandas da população.

\section{Federalismo e Educação}

A compreensão do estágio em que se encontra a educação brasileira está vinculada às características do modelo federalista que se desenvolve no país, tendo em vista o impacto dessa forma de organização para a criação e implementação de políticas públicas para o setor da educação e a repercussão destas nos estados, municípios e distrito federal.

A Constituição de 1988 deixa claro, no artigo 211, que "a União, os Estados e os Municípios organizarão em regime de colaboração seus sistemas de ensino". Assim, sendo a educação afeita a todos os entes federativos, diz-se que ela é uma matéria de natureza concorrencial. O regime de colaboração, que deve ser recíproco, supõe normas e finalidades gerais, mediante ações articuladas e compromissadas entre os entes federados na repartição de responsabilidades e competências na prestação de serviços, neste caso, educacionais. Esse dispositivo da Carta original de 1988 nos remete à reflexão, a partir de uma citação de Bobbio (1997, p. 101):

Limito-me a observar que, por reação a esse fenômeno difuso de responsabilidade coletiva, no qual ninguém é responsável e responsáveis são sempre os outros, é frequentemente a afirmação igualmente falsa de que, somos todos responsáveis, uma assunção genérica, generalizada e além do mais evasiva de uma culpa coletiva segundo a qual, ainda uma vez, sendo todos culpados, ninguém é culpado.

Por esse motivo, alguns autores, dentre esses Gilda Cardoso de Araújo (2005) e Maria Couto Cunha (2007) afirmaram que a Constituição de 1988 se caracteriza pela definição imprecisa quanto ao regime de colaboração, vez que situa o Poder Público como responsável por assegurar o direito à educação, com uma organização extremamente descentralizada, sem definir, de forma clara, as competências dos entes federados na prestação desses serviços. Faria (2006), também alerta que as implicações políticas e sociais que delimitam a questão local no Brasil estão diretamente ligadas ao modelo do federalismo adotado.

A Constituição de 1988 ampliou a faculdade de se governar dos Municípios e dispôs para eles no campo educacional uma relativa autonomia. No entanto, somente a partir das diretrizes gerais estabelecidas na Lei de Diretrizes e Bases da Educação Nacional 9394/96, ficou explícita a possibilidade de livre organização de seus sistemas de ensino à União, aos Estados e aos Municípios, obedecendo as suas prioridades, estabelecendo ainda para os municípios a atribuição de integração de seus órgãos e instituições oficiais às políticas e planos educacionais da União e dos Estados, ressaltando a integração entre os sistemas mediante regime de colaboração. 
A Emenda Constitucional 14/96 ${ }^{9}$ e, mais recentemente, a Emenda Constitucional $53 / 2006^{10}$, apesar de se caracterizarem como estratégias indutivas de responsabilização do ensino fundamental e educação infantil pelos municípios, também podem ser consideradas instrumentos legais na tentativa de definição do regime de colaboração entre os entes federados (DUARTE, 2005). Todavia, mesmo situando o papel suplementar da União, manteve a necessidade de explicitação das diretrizes operacionais para a efetivação do regime de colaboração entre Estados e Municípios. Somam-se a isso, as conclusões feitas por alguns autores de que esses mecanismos do governo federal na área educacional, como é o caso da política de fundos na educação, trazem muito pouco dinheiro novo no caixa municipal, exceto nos municípios mais pobres (DAVIES, 1998; SOUZA, C., 2004). Já dizia Bobbio (1997, p. 36): "[...] uma sociedade torna-se tanto mais ingovernável quanto mais aumentam as demandas da sociedade civil e, não aumenta correspondentemente a capacidade das instituições de a elas responder".

Assim, políticas apontadas como mecanismos de superação de constrangimento financeiros entre entes federados foram engendradas pelo governo federal, através da adoção de novos desenhos e formas de financiamento, visando à municipalização da provisão de serviços sociais.

Anteriormente à introdução desses novos desenhos, era comum a acusação de que a Constituição de 1988 havia transferido recursos, mas não competências, para os governos subnacionais.

9 A Emenda Constitucional 14/96, criou um Fundão, subvinculando $15 \%$ do ICMS - Imposto sobre Circulação de Mercadorias e sobre Prestação de Serviços (ICMS), do Fundo de Participação dos Estados e Municípios (FPE/FPM) e do Imposto de Produtos Industrializados (IPI) para exportação para a manutenção e desenvolvimento do ensino fundamental.

10 A Emenda Constitucional 53/06 criou um Fundo nos moldes da EC 14/96, subvinculando $20 \%$, a partir do terceiro ano em vigor, do Imposto sobre Circulação de Mercadorias e sobre Prestação de Serviços (ICMS), do Fundo de Participação dos Estados e Municípios (FPE/FPM) e do Imposto de Produtos Industrializados (IPI) para exportação, do Imposto sobre Circulação de Veículos Automotores (IPVA), do Imposto Territorial Rural (ITR), do Imposto sobre Transmissão Causa Mortis (ITCM), para a manutenção e desenvolvimento de toda a educação básica.
No entanto, a experiência brasileira demonstra que a questão da transferência de responsabilidades, pela provisão de serviços sociais, em especial a educação, entendida como estratégia de descentralização, não se restringe à existência de mais recursos financeiros. Reportando sobre como se caracteriza o repasse das atribuições do governo central para os níveis subnacionais, Rodden (2005, p. 15) esclarece que

[...] muito raramente os governos centrais cedem autonomia plena aos governos subnacionais. Na vasta maioria dos casos, a descentralização envolve um movimento de uma situação de completo controle do governo central para a de um envolvimento conjunto entre o centro e uma ou mais unidades subnacionais.

No caso brasileiro, a União reservou para si algumas atribuições que configuram o controle explicitado por essa citação de Rodden(2005), entre elas destacam-se: a regulamentação do sistema educacional (duração da educação obrigatória, credenciamento de instituições educacionais, parâmetros curriculares nacionais, definição da qualificação docente mínima, exigências para passar de um nível a outro, estabelecimento de normas gerais sobre validação de títulos etc.); função supletiva e redistributiva dos recursos financeiros; desenvolvimento e manutenção de sistema de informação sobre educação; desenvolvimento de avaliações em todos os níveis; provisão de ensino técnico; aplicação da política do livro didático, entre outros (MORDUCHOWICZ; ARANGO, 2010).

Aos municípios foram lançadas as possibilidades de escolha sobre a construção de um sistema educacional próprio ou se associar ao sistema estadual e entre as competências atribuídas por lei para essa instância está a provisão da educação infantil e do ensino fundamental. Contudo, há constantes apelos para o desenvolvimento de parcerias para ofertar ensino médio (Projeto Ensino Médio no Campo) e educação superior (Universidade Aberta do Brasil) ambos com implicações financeiras e de pessoal para a gestão municipal.

\section{Consideraçõs Finais}

O federalismo é, pois, umas das formas de distribuição das competências no âmbito da 
ordem jurídica do Estado que se opõe ao Estadoúnico. Trata-se de um arranjo complexo, no qual a existência de mais de um poder sobre o mesmo território resulta na necessidade de constante cooperação para evitar, de um lado o conflito de competências e, de outro, a supremacia de um poder sobre os demais.

Podemos considerar que o texto constitucional aprovado em 1988 inovou ao incluir o município como um terceiro ente federado, caso único nas federações existentes, além de atribuirIhe protagonismo na descentralização de competências, principalmente na área social. A valorização dos governos municipais na América Latina guarda sua origem, simultaneamente, nos processos de redemocratização, impulsionados a partir da década de 1970, e na reestruturação produtiva por que passa a economia capitalista nesse período. Assim, esse fenômeno opera em duplo movimento: "por um lado a redefinição das bases de intervenção do Estado na esfera social e por outro, as mudanças organizacionais e de gestão no setor público" (DUARTE, 2001, p. 1).

Todavia, se, por um lado, isso repercutiu na possibilidade da participação direta do cidadão na gestão dos serviços públicos, por outro, significou a ampliação das dificuldades na tentativa do estabelecimento do equilíbrio federativo e de medidas de igualdade na prestação dos serviços públicos à população, tendo em vista a diversidade das demandas e da capacidade orçamentária dos 27 estados e dos 5.564 municípios brasileiros (ARAÚJO, 2006).

A ausência de uma ação coordenada no processo de descentralização, iniciado a partir de 1988, é apontada por alguns estudiosos, dentre estes Santos e Ribeiro (2004), como fator que tem estimulado o surgimento de atribuições concorrentes entre as distintas instâncias do governo. Nesse contexto, Estados e Municípios não conseguem definir com clareza seus papéis e, dentro desse ambiente de profunda competição, Ihes faltam, na maioria das vezes, não somente as condições técnicas (político-administrativas) como, principalmente, as financeiras. Segundo esses mesmos autores:

Assiste-se a partir desse momento ao acirramento do conflito federativo e, embora as instâncias subnacionais tenham ampliado significativamente os seus gastos inclusive na área social, estão muito longe de cobrir as imensas necessidades atuais, especialmente em áreas mais pobres como 0 Nordeste, onde a grande maioria dos municípios se encontra em condições de alto grau de dependência financeira e indigência social (SANTOS; RIBEIRO, 2004, p. 252).

Diante disso, o grande desafio reside em conciliar a crescente demanda por serviços básicos (saúde, educação, habitação, segurança, etc.) e o compartilhamento de ações entre os entes federados, vez que o processo de descentralização tem focalizado o município como o principal responsável pela gestão e execução de políticas públicas, condicionando $\mathrm{o}$ desenvolvimento local à capacidade deste em firmar parcerias e convênios com outras instâncias da federação. Nesse aspecto, convém uma análise que envolva a capacidade de articulação política dos municípios brasileiros e as possibilidades de promover $\mathrm{o}$ desenvolvimento local via regime de cooperação. Para tanto, é preciso focalizar os procedimentos de construção das políticas municipais de educação, por meio de seus planos de gestão, bem como os critérios para a seleção das prioridades e estratégias para alcance das competências que Ihes confere o pacto federativo.

\section{Referências Bibliográficas}

ARAUJO, Gilda Cardoso de. Município, federação e educação: instituições e ideias políticas no Brasil. In: REUNIÃO ANUAL DA ANPED, 29., 2006, Caxambu. Anais eletrônicos... Caxambu, MG: ANPED, 2006. Disponível em: <www.anped.org.br/reunioes/29ra/trabalhos/trabalho/GT05- 1909-Res.pdfs. Acesso em: 10 jun. 2010.

Município, federação e educação: história das instituiçõos e das ideias políticas no Brasil. 2005. 331 f. Tese (Doutorado) - Faculdade de Educação, Universidade de São Paulo (USP), São Paulo, 2005.

ARRETCHE, Marta T. S. Relações federativas nas politicas sociais. Educação e Sociedade, Campinas, SP, v. 23, n. 80, p.25-48, set. 2002. Disponível em: $<$ <htp://www.scielo.br/pdf/es/223n80/12922.pdfs. Acesso em: 10 jun. 2010. 
Políticas sociais no Brasil: descentralização em um estado federativo. Revista Brasileira de Ciências Sociais, São Paulo, v. 14, n. 40, p. 111-141, jun. 1999. Disponível em: <http://www.scielo.br/pdf/rbcsoc/v14n40/1712.pdfs. Acesso em: 14 mai. 2010.

BARRETO, Maria Inês; VIGEVANI, Tullo. Cenário global e o espaço de intervenção dos governos locais. In: MARTINS, Ângela Maria; OLIVEIRA, Cleiton de; BUENO, Maria Sylvia Simões (Org.). Descentralização do estado e municipalização do ensino: problemas e perspectivas. Rio de Janeiro: DP\&A, 2004.

BOBBIO, Norberto. Os intelectuais e o poder: dúvidas e opções dos homens de cultura na sociedade contemporânea. São Paulo: Editora UNESP, 1997.

\section{CASSEB, Paulo A. Federalismo. Aspectos contemporâneos. Coleção saber jurídico. São Paulo: Juarez de Oliveira, 1999.}

CUNHA, Maria Couto. Relações intergovernamentais, políticas de descentralização e gestão da educação municipal. In: SIMPÓSIO BRASILEIRO DE POLÍTICA E ADMINISTRAÇÃO DE EDUCAÇÃO, 23., 2007, Porto Alegre. Anais eletrônicos... Porto Alegre: ANPAE, 2007. Disponível em: <http:// uww.isecure.com.br/anpae/277.pdf>. Acesso em: 15 mai. 2010.

CURY, Carlos Roberto Jamil. Federalismo político e educacional. In: FERREIRA, Naura Syria Carapeto (Org.). Políticas públicas e gestão da educação. Brasilia: Líber Livro, 2006.

DAVIES, Nicholas. O FUNDEF e o orçamento da educação: desvendando a caixa preta. Campinas, SP: Autores Associados, 1998.

DUARTE, M. R. T. Regulação sistêmica e política de financiamento da educação básica. Educação e Sociedade, Campinas, SP, v. 26, n. 92, p. 821839, out.2005. Disponível em: <http://www.scielo.br/pdf/es/v26n92/v26n92a06.pdf >. Acesso em: 05 mai. 2010.

. Relações intergovernamentais e regime de colaboração: 0 atendimento público na educação escolar básica. In: REUNIÃO ANUAL DA ANPED, 24, 2001, Caxambu. Anais eletrônicos... Caxambu, MG: ANPED, 2001. Disponível em: <http://www.anped.org.br/24/T0593764807949. doc $>$. Acesso em: 21 abr. 2010

EGLER, Cláudio; MATTOS, Margarida. Federalismo e gestão do teritório: as regiões integradas de desenvolvimento. In: ENCONTRO NACIONAL DA ASSOCIAÇÃO DE PÓS GRADUAÇÃO E PESQUISA EM GEOGRAFIA, 5., 2003, Florianópolis. Anais

eletrônicos... Rio de Janeiro: UFRJ, 2003. Disponível em: <http://www.laget.igeo.ufrj.br/egler/pdt/ANPEGE_1.pdf.> Acesso em: 15 mai. 2010.

FARIA, Lia. A questão local: um debate para a educação. Revista Brasileira de Política e Administração da Educação, Porto Alegre, v. 22, n. 1, p. 67-84, jan.jjun. 2006.

MORDUCHOWICZ, Alejandro; ARANGO, Aída. Desenho institucional e articulação do federalismo educativo: experiências internacionais. In: OLIVEIRA, Romualdo Portela de; SANTANA, Wagner.(orgs.). Educação e federalismo no Brasil: combater as desigualdades, garantir a diversidade. - Brasilia: UNESCO, 2010.

RODDEN, Jonathan. Federalismo e descentralização em perspectiva comparada: sobre significados e medidas. Revista de Sociologia e Política, Curitiba, n. 24, p. 9-27, jun. 2005.

SAVIANI, Dermeval. A nova lei da educação: LDB, trajetória, limites e perspectivas. 2. ed. Campinas, SP: Autores Associados, 1997.

SOUZA, Celina. Intermediação de interesses regionais no Brasil: o impacto do federalismo e da descentralização. Dados: Revista de Ciências Sociais, v. 41, n. 3, p. 569-591, jan. 1998.

Governos locais e gestão de polticas sociais universais. São Paulo em Perspectiva, v. 18, n. 02, p. 27-41, 2004.

SANTOS, Reginaldo Souza; RIBEIRO, Elizabeth Matos. As impossibilidades do projeto descentralizante do Brasil. In: SUPERINTENDÊNCIA DE ESTUDOS ECONÔMICOS E SOCIAIS DA BAHIA (SEI). Desigualdades regionais. Salvador, 2004. p. 251-274.

TOMI0, Fabrício Ricardo de Limas. Autonomia municipal e criação de governos locais: a peculiaridade institucional brasileira. Revista da Faculdade de Direito da Universidade Federal do Paraná, n. 42, p. 103-120, 2005.

WATTS, R. The Relevance Today of the Federal Idea. In: INTERNATIONAL CONFERENCE ON FEDERALISM, Switzerland, 2002. Proceeding... Ontario, Canada: Forum of Federations, 2002. Disponível em: 〈http://www.forumfed.org/en/federalism/federalismtoday.php>. Acesso em: 08 de jun. 2010.

Recebido em junho de 2010

Aprovado em agosto de 2010 